\title{
Design and evaluation of a recombinant multi-epitope antigen for serodiagnosis of Toxoplasma gondii infection in humans
}

\author{
Khalid Hajissa', Robaiza Zakaria', Rapeah Suppian² and Zeehaida Mohamed ${ }^{1 *}$
}

\begin{abstract}
Background: Serological investigation remains the primary approach to achieve satisfactory results in Toxoplasma gondii identification. However, the accuracy of the native antigen used in the current diagnostic kits has proven to be insufficient as well as difficult to standardize, so significant efforts have been made to find alternative reagents as capture antigens. Consequently, multi-epitope peptides are promising diagnostic markers, with the potential for improving the accuracy of diagnostic kits. In this study, we described a simple, inexpensive and improved strategy to acquire such diagnostic markers. The study was aimed at producing novel synthetic protein consisting of multiple immunodominant epitopes of several T. gondii antigens.
\end{abstract}

Findings: To accomplish our goals, a single synthetic gene of approximately $456 \mathrm{bp}$, which encodes potential epitopes of T. gondii antigens, was successfully constructed using gene assembly PCR. The constructed gene was cloned into a PET32a expression vector and transformed into BL21 E. coli. The entire protein was successfully expressed and purified. Subsequently, the preliminary diagnostic performance of expressed protein was evaluated by developing IgG enzyme-linked immunosorbent assay (ELISA) and Western blot analysis using human sera. The results showed $100 \%$ sensitivity and specificity.

Conclusion: A purified protein expressing multi-immunodominant epitopes of T. gondii was generated. Further studies are required to evaluate the immunogenicity in animal models and to verify the immuno-reactivity of USM.TOXO1 as a diagnostic antigen.

Keywords: Assembly PCR, Epitopes, Synthetic gene, Toxoplasma gondii, USM.TOXO1

\section{Findings}

\section{Background}

Toxoplasmosis is a widespread parasitic disease caused by the intracellular protozoan parasite Toxoplasma gondii $[1,2]$. The primary infection in healthy individuals is usually asymptomatic but severe clinical signs can be associated with the disease in immunocompromised patients [3-5]. Therefore, the development of simple, rapid, and sensitive diagnostic tests for $T$. gondii identification is crucial to reduce the risk of the disease in such patients [6].

The serological investigation of $T$. gondii remains the primary approach to achieve satisfactory results $[7,8]$; however, producing reliable reagents and standard antigens

\footnotetext{
* Correspondence: zeehaida@usm.my

${ }^{1}$ Department of Medical Microbiology \& Parasitology, School of Medical Sciences, Universiti Sains Malaysia, 16150 Kubang Kerian, Kelantan, Malaysia Full list of author information is available at the end of the article
}

remains difficult and expensive [6]. Currently, the use of crude native antigens in diagnostic methods has an important effect on the standardization of diagnostic tests as well as on the price of these kits.

In this sense, it is assumed that replacing this antigen in all current diagnostic kits with standard reagents will achieve a highly sensitive and specific diagnostic assay [9], and therefore significant efforts have been made to identify alternative capture antigens. As a result, a multiepitope-based antigen approach using software-based prediction tools and molecular techniques may provide a novel and alternative means of acquiring less expensive and more accurate diagnostic kits $[6,10]$. Furthermore, experimental evidence suggests that application of peptidebased antigen can meet the demand of serological test standardization and increase the sensitivity and specificity of these tests $[9,11,12]$. Consequently, assays based on 
such antigens are expected to be more sensitive and easier to standardize. Multi-epitope antigen as a potential capture antigen has been evaluated in several studies for different pathogens $[9,12-16]$, including T. gondii infection $[6,10$, $11,17,18]$.

This study aimed to construct a synthetic gene that encodes multi-immuno-dominant epitopes of three $T$. gondii antigens by simple, inexpensive, and improved strategy for design and construction of a multi-epitope gene for acquirement of novel and promising diagnostic marker and vaccine candidate.

\section{Methods}

Full amino acid sequences of SAG1, GRA2, and GRA7 were retrieved from the GenBank database. The immunodominant epitopes expressed within these antigens were identified by the $\mathrm{ABCpred}$ online prediction server [19]. Subsequently, three potential epitopes with high antigenicity and immunogenicity scores from each antigen were selected (Table 1). The epitopes were then combined in a manner that facilitated the design of the complementary oligonucleotides (Fig. 1). Finally, based on the DNA sequence of the predicted epitopes, a $456 \mathrm{bp}$ synthetic gene (USM.TOXO1) was designed using VNTI computer program software (Life Technologies, USA).

Subsequently, 19 overlapping, single-stranded DNA oligonucleotides (24-44 nt. in length) were designed and used to construct the USM.TOXO1 gene synthetically by assembly PCR, as described by Stemmer [20]. The synthetic gene was then cloned into a pET-32a expression vector (Novagen, USA). Consequently, the recombinant plasmid was transformed into E. coli BL21 (DE3) plysS competent cells (Novagen, USA). Following the confirmation of the sequences of inserts by DNA sequencing (IDT, Singapore), the protein expression was induced by isopropyl-D thiogalactopyranoside (IPTG) with a final concentration of $1 \mathrm{mM}$. Directly after purification of the synthetic protein by Ni-NTA column, SDS-PAGE and Western blot analysis were carried out to verify the expression of the candidate

Table 1 Amino acid sequence of 9 epitopes of three T. gondii antigen predicted by ABCpred

\begin{tabular}{lllcc}
\hline Gene & Predicted epitope & Sequence & Start position & Score \\
\hline SAG1 & SAG1_EP1 & KLSAEGPTTMTLVCGK & 202 & 0.91 \\
& SAG1_EP2 & AAVILTPTENHFTLKC & 67 & 0.89 \\
& SAG1_EP3 & TEPPTLAYSPNRQICP & 88 & 0.88 \\
GRA2 & GRA2_EP1 & DERQQEPEEPVSQRAS & 61 & 0.92 \\
& GRA2_EP2 & TQAPDSPNGLAETQAP & 153 & 0.89 \\
& GRA2_EP3 & GWNQGPVDVPFSGKP & 28 & 0.87 \\
GRA7 & GRA7_EP1 & AATASDDELMSRIRNS & 26 & 0.93 \\
& GRA7_EP2 & MGLTRTYRHFSPRKNR & 199 & 0.93 \\
& GRA7_EP3 & PELTEEQQRGDEPLTT & 162 & 0.91 \\
\hline
\end{tabular}

protein. In the western blot analysis, the purified protein was transferred to polyvinylidene fluoride (PVDF) membrane and then blocked with $3 \%$ BSA in PBS for $1 \mathrm{~h}$. The membrane was incubated with $T$. gondii-positive or negative human sera (1:100 dilution in blocking solution) or anti-histidine antibody (1:2500) for $1 \mathrm{~h}$ at room temperature. Bound antibodies were detected with HRP conjugated goat anti-human IgG and anti-mouse IgG (1:5000, Santa Cruz Biotechnology, Germany).

The preliminary integrity of the purified protein as a diagnostic marker was evaluated by immunoblotting and ELISA. For the ELISA analysis, diluted serum (1:100) from T.gondii sero-positive and sero-negative patients was used as the primary antibody. Briefly, $10 \mu \mathrm{g} / \mathrm{ml}$ of USM.TOXO1 synthetic protein was prepared in $100 \mu \mathrm{l}$ of $0.05 \mathrm{M}$ carbonate buffer ( $\mathrm{pH}$ 9.6) and coated onto microtiter plates then incubated overnight at $4{ }^{\circ} \mathrm{C}$. The plate was then washed $(\times 3)$ with PBS-T for $5 \mathrm{~min}$ each time, the wells were blocked with PBS containing $3 \%$ bovine serum albumin at $37{ }^{\circ} \mathrm{C}$ for $1 \mathrm{~h}$, another three rounds of washes were carried out before the diluted human sera was added and incubated at $37{ }^{\circ} \mathrm{C}$ for $1 \mathrm{~h}$. After three washings with PBS-T, a secondary anti-human IgG conjugated with horseradish peroxidase was added and incubated at $37{ }^{\circ} \mathrm{C}$ for $1 \mathrm{~h}$. After final washing, TMB substrate was added and incubated for $15 \mathrm{~min}$. The reaction was stopped by the addition of $2 \mathrm{M} \mathrm{H}_{2} \mathrm{SO}_{4}$. The optical density (OD) was then measured by using SpectraMax M Series Multi-Mode Microplate Readers (USA).

\section{Ethical approval}

The study protocol was approved by Human Research Ethics Committee Universiti Sains Malaysia (HREC) (Approval number USM/JEPeM/15020034).

\section{Results}

This study produced a single protein expressing nine immunodominant epitopes of T. gondii antigens. Briefly, USM.TOXO1 synthetic gene was designed using VNTI software based on the DNA sequence of the predicted epitopes. Subsequently, a mixture of 19 single-stranded DNA oligonucleotides was used in the assembly PCR reaction. A 456 bp synthetic gene was successfully amplified in the second PCR from the collection of DNA fragments generated by assembly PCR. Following the induction of the expression in BL21 E. coli, SDSPAGE and Western blot analysis allowed successful identification of the purified synthetic protein (Fig. 2). The preliminary diagnostic performance of the developed ELISA, using 40 positive and 40 negative serum samples, showed highly immunoreactivity performance of these synthetic proteins. 


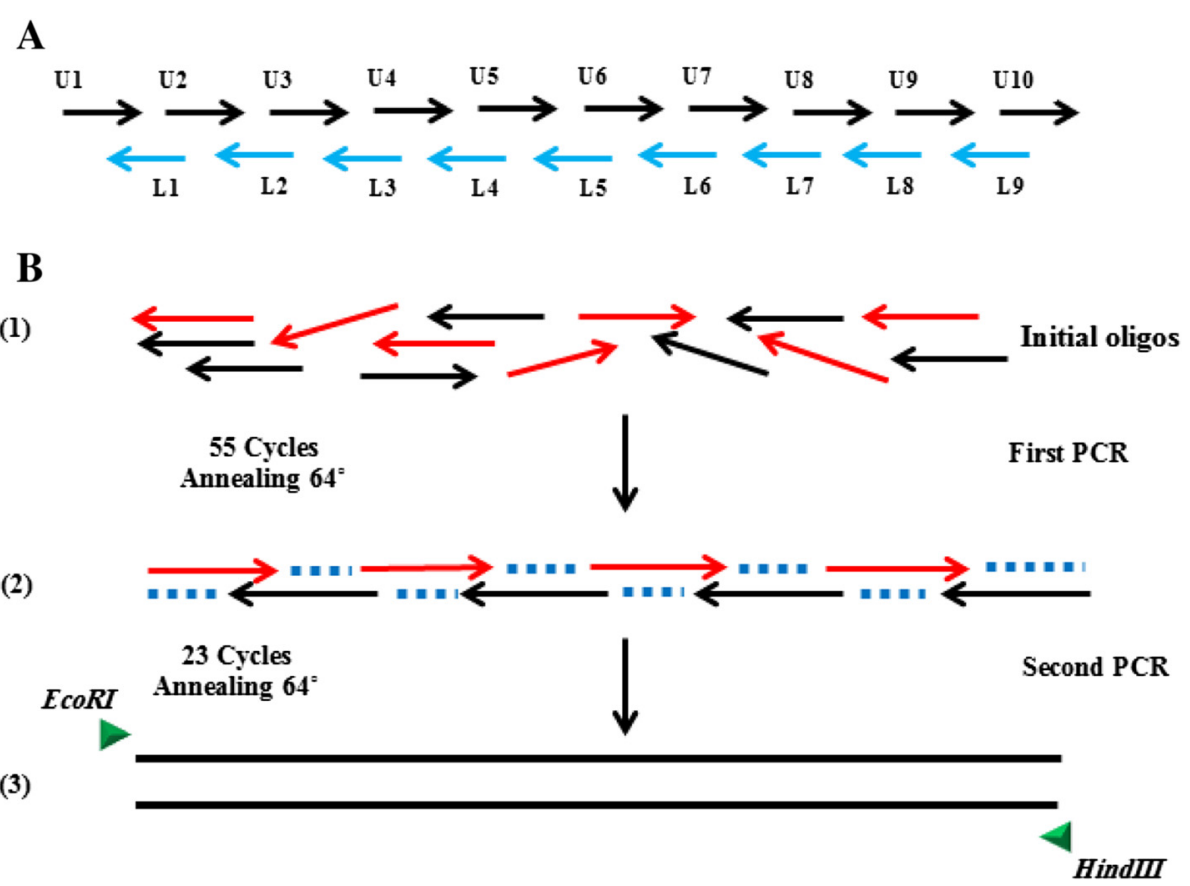

Fig. 1 Schematic diagram of synthetic gene USM.TOXO1 construction; a Oligonucleotides design, U1-U10 is sense-strand primers. L1-L9 antisense-strand primers. b Assembly PCR steps 1: Oligos mixture 2: Gene assembly 3: Gene amplification

\section{Discussion}

Up to date, most of the current diagnostic kits use crude Toxoplasma antigens [6, 9, 21]. Unfortunately, application of tachyzoite crude antigen in diagnostic assays is not only associated with sensitivity and specificity problems but also with difficulties in standardization and cost effectiveness [9]. To overcome this limitation, epitopes can standardize diagnostic methods and increase the sensitivity and specificity of these tests $[19,22]$.

Bioinformatics tools are widely applied for epitope identification in protein analysis. Moreover, various epitope peptides are used to develop diagnostic antigen and epitope-based vaccines $[6,10,14]$. By using softwarebased prediction techniques, the epitopes of several $T$. gondii antigen were predicted and their antigenicity evaluated; for example, SAG1 [17] and GRA1 [10, 11, 18]. The newly synthesized immunodominant epitopes within T. gondii antigens SAG1, SAG2, SAG3, GRA5, GRA6, and P35 have the potential to be novel diagnostic antigens for the achievement of accurate diagnostic kits [6]. Moreover, peptide epitopes are effective in discriminating between recently acquired infection and past infection; thus, they can serve as effective tools for toxoplasmosis screening $[6,11]$.

High diagnostic performance can be achieved by using different epitopes as diagnostic markers. Alternatively, the use of a multi-epitope peptide that expresses a high density of conserved antigenic determinant can contribute to the achievement of a high degree of sensitivity and specificity [9].

Current attempts at producing epitope-based antigens are based on direct PCR amplification of single peptide for DNA template [9] chemical synthesis [10, 11, 14], splicing by overlap extension (SOEing) [16], or by synthesis of two complementary single-stranded DNA oligonucleotides based on the DNA sequences of the identified epitopes. The oligonucleotides will then anneal to generate double-stranded DNA that encodes for the predicted epitope. However, the use of this approach necessitates joining the individual peptide with a linker to construct multi-epitope peptides [6].

In general, the conventional production of multi-epitope peptides as mentioned above has been proven to be timeconsuming, complex, and costly. In this study, assembly PCR was applied to generate a synthetic gene, a simple and cost effective method that relies on constructing a single synthetic gene encoding multi-immunodominant epitope peptides as a new strategy for developing effective and standard diagnostic markers [23]. Assembly PCR is a flexible technique that can be used for producing long DNA sequence from single-stranded oligos or a mixture of single and double-stranded DNA [20]. The approach is very interesting because overlapping regions can be joined without the need of DNA ligation. Interestingly, the most significant advantage of synthetic gene construction is that a DNA template is not required, 


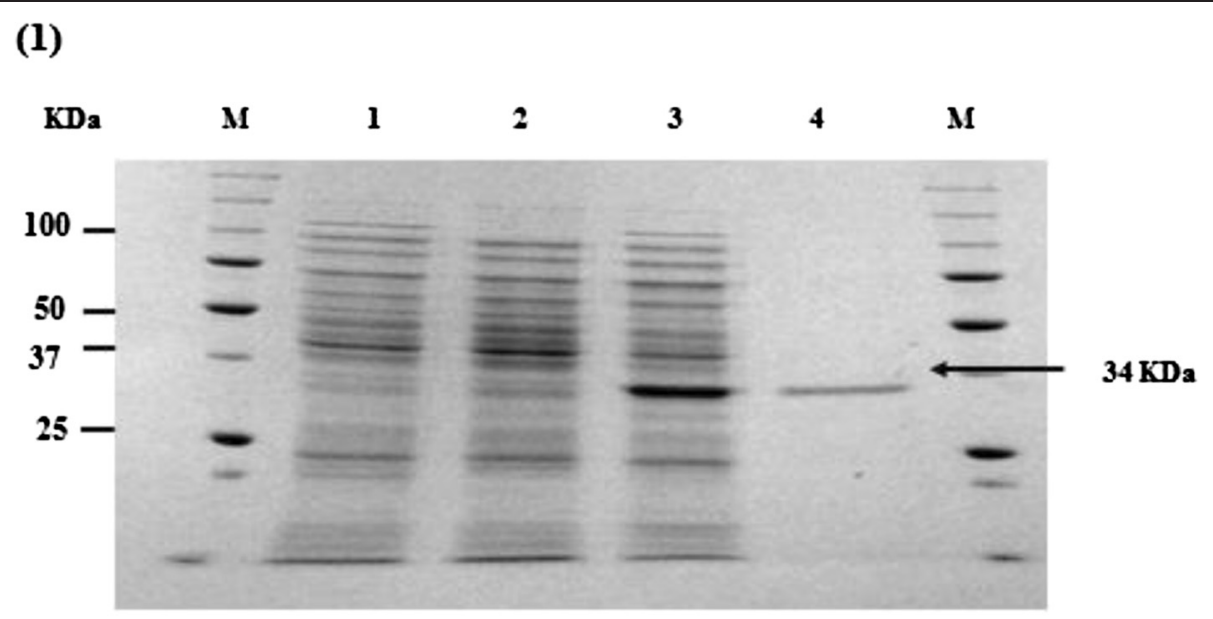

(2)

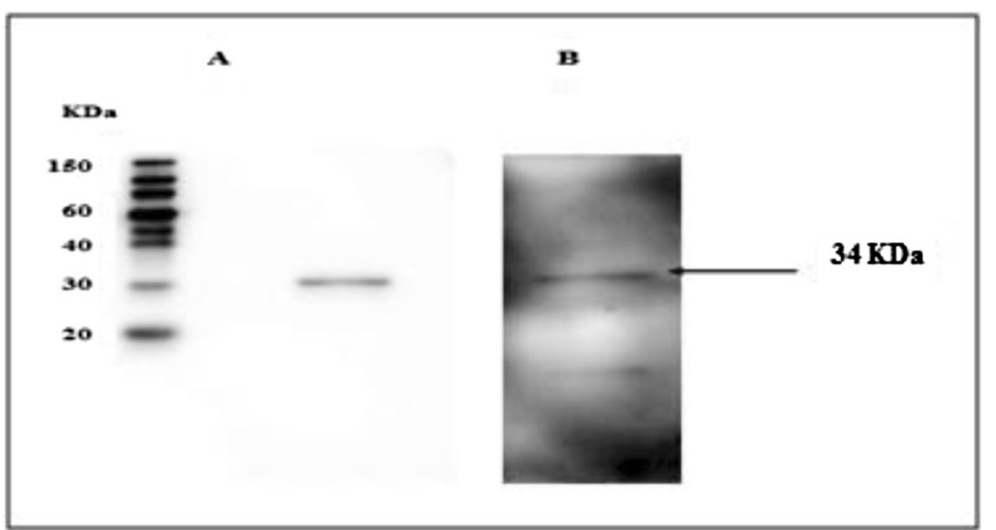

Fig. 2 SDS-PAGE and WB Analysis of USMTOXO1 expressions in BL21 pLysS (DE3), 1 Coomassie blue stained; Lane M: molecular weight marker, Lane 1: lysate of IPTG-induced E.coli containing vector without insert, Lane 2: lysate of non-induced E.coli containing vector with insert, Lane 3: lysate of IPTG-induced E.coli containing vector with insert, Lane 4: purified USMTOXO1 synthetic protein $\mathbf{2}$ Western-blot analysis of purified USM.TOXO1; detected by (A) anti-His antibody (B) human sera

which is particularly helpful if the organism of interest has no readily available sequence information.

To the best of our knowledge, the production of a single synthetic gene that encodes multi-epitopes of several $T$. gondii antigens was generated for the first time in this study. Thus, the USM.TOXO1 synthetic gene is the primary product of using assembly PCR to assemble different immunodominant epitopes from different antigens in a single protein. Therefore, assembly PCR appears to be very efficient in obtaining a synthetic protein that expresses a high density of conserved antigenic determinant that can contribute to achieving sensitive and specific serodiagnostic methods.

Given that the objective of producing multi-epitope antigens is to investigate their potential application in the detection of toxoplasmosis infection, the ability of USM.TOXO1 antigen to detect anti-Toxoplasma antibodies was tested by western blot and ELISA analysis. In addition, the results suggest that the immuno-reactivity of the synthetic protein as a capture antigen to specifically detect serum $T$. gondii antibodies is promising. The generated recombinant multi-epitope peptide is considered useful, and further investigation into the development of accurate diagnostic kits is recommended.

\section{Conclusion}

In conclusion, the recombinant proteins containing different antigenic determinants of three $T$. gondii antigens were generated. Results suggested that the performance of the generated multi-immuno-dominant epitopes in serodiagnosis has great potential for the development of accurate diagnostic kits. The synthetic protein yielded better results; in that it promises the improvement of current diagnostic assay by applying such antigens. However, the limited serum samples used in this study are not sufficient to give a final assessment of diagnostic utility of this synthetic protein. Further investigation with large-scale sample sizes and IgM-positive serum is required. 


\section{Consent}

Written informed consent was obtained from the patient for the publication of this report and any accompanying images.

\section{Competing interests}

The authors declare that they have no competing interests.

\section{Authors' contributions}

$\mathrm{KH}$, performed the experiments, RZ, RS, ZM designed the study, carried out the troubleshooting of the lab work and critically revised the manuscript. All authors read and approved the final manuscript.

\section{Acknowledgments}

This work was supported by the Universiti Sains Malaysia Short Term grant No. 304/PPSP/61313073.

\section{Author details}

${ }^{1}$ Department of Medical Microbiology \& Parasitology, School of Medical Sciences, Universiti Sains Malaysia, 16150 Kubang Kerian, Kelantan, Malaysia. ${ }^{2}$ Biomedicine Program, School of Health Sciences, Universiti Sains Malaysia, 16150 Kubang Kerian, Kelantan, Malaysia.

Received: 14 April 2015 Accepted: 2 June 2015

Published online: 11 June 2015

\section{References}

1. Buffolano W, Beghetto E, Del Pezzo M, Spadoni A, Di Cristina M, Petersen E, et al. Use of recombinant antigens for early postnatal diagnosis of congenital toxoplasmosis. J Clin Microbiol. 2005;43(12):5916-24.

2. Murat JB, Souvignet A, Fricker-Hidalgo H, Brenier-Pinchart MP, Bost-Bru C, Pelloux $\mathrm{H}$. Assessment of the IgA immunosorbent agglutination assay for the diagnosis of congenital toxoplasmosis on a series of 145 toxoplasmic seroconversions. Clin Vaccine Immunol. 2015;22(4):456-8.

3. Macêdo AG, Cunha JP, Cardoso THS, Silva MV, Santiago FM, Silva JS, et al. SAG2A protein from Toxoplasma gondii interacts with both innate and adaptive immune compartments of infected hosts. Parasit Vectors. 2013;6:163.

4. Ajzenberg D, Yera H, Marty P, Paris L, Dalle F, Menotti J, et al. Genotype of 88 Toxoplasma gondii isolates associated with toxoplasmosis in immunocompromised patients and correlation with clinical findings. J Infect Dis. 2009:199(8):1155-67.

5. Fricker-Hidalgo H, Cimon B, Chemla C, Darde ML, Delhaes L, L'Ollivier C, et al. Toxoplasma seroconversion with negative or transient immunoglobulin $\mathrm{M}$ in pregnant women: myth or reality? A French multicenter retrospective study. J Clin Microbiol. 2013:51(7):2103-11. doi:10.1128/JCM.00169-13.

6. Dai J, Jiang M, Wang Y, Qu L, Gong R, Si J. Evaluation of a recombinant multiepitope peptide for serodiagnosis of Toxoplasma gondii infection. Clin Vaccine Immunol. 2012;19(3):338-42.

7. Rorman E, Zamir CS, Rilkis I, Ben-David H. Congenital toxoplasmosis-prenatal aspects of Toxoplasma gondii infection. Reprod Toxicol. 2006;21(4):458-72.

8. Wong SY, Hajdu MP, Ramirez R, Thulliez P, McLeod R, Remington JS. Role of specific immunoglobulin $\mathrm{E}$ in diagnosis of acute toxoplasma infection and toxoplasmosis. J Clin Microbiol. 1993;31(11):2952-9.

9. Camussone C, Gonzalez V, Belluzo MS, Pujato N, Ribone ME, Lagier CM, et al. Comparison of recombinant Trypanosoma cruzi peptide mixtures versus multiepitope chimeric proteins as sensitizing antigens for immunodiagnosis. Clin Vaccine Immunol. 2009;16(6):899-905.

10. Wang $Y$, Wang G, Ou J, Yin H, Zhang D. Analyzing and identifying novel B cell epitopes within Toxoplasma gondii GRA4. Parasit Vectors. 2014;7(1):474

11. Wang $Y$, Wang G, Zhang D, Yin H, Wang M. Screening and identification of novel B cell epitopes of Toxoplasma gondii SAG1. Parasit Vectors. 2013;6:125.

12. Xa L, Chen $Y$, Yan J. Recombinant multiepitope protein for diagnosis of leptospirosis. Clin Vaccine Immunol. 2008:15(11):1711-4.

13. Dipti CA, Jain S, Navin K. A novel recombinant multiepitope protein as a hepatitis $C$ diagnostic intermediate of high sensitivity and specificity. Protein Expr Purif. 2006;47(1):319-28.

14. Menezes-Souza D, de Oliveira Mendes TA, Nagem RAP, de Oliveira Santos $\Pi$, Silva ALT, Santoro MM, et al. Mapping B-cell epitopes for the peroxidoxin of Leishmania (Viannia) braziliensis and its potential for the clinical diagnosis of tegumentary and visceral leishmaniasis. PloS One. 2014;9(6), e99216.
15. Duthie MS, Hay MN, Morales CZ, Carter L, Mohamath R, Ito L, et al. Rational design and evaluation of a multiepitope chimeric fusion protein with the potential for leprosy diagnosis. Clin Vaccine Immunol. 2010;17(2):298-303.

16. Cheng Z, Zhao JW, Sun ZQ, Song YZ, Sun QW, Zhang XY, et al. Evaluation of a novel fusion protein antigen for rapid serodiagnosis of tuberculosis. J Clin Lab Anal. 2011;25(5):344-9.

17. Beghetto E, Pucci A, Minenkova O, Spadoni A, Bruno L, Buffolano W, et al. Identification of a human immunodominant B-cell epitope within the GRA1 antigen of Toxoplasma gondii by phage display of cDNA libraries. Int J Parasitol. 2001:31(14):1659-68.

18. Wang $Y$, Wang $G$, Zhang D, Yin H, Wang M. Identification of novel B cell epitopes within Toxoplasma gondii GRA1. Exp Parasitol. 2013;135(3):606-10.

19. Saha S, Raghava G. Prediction of continuous B cell epitopes in an antigen using recurrent neural network. Proteins. 2006;65(1):40-8.

20. Stemmer WP, Crameri A, Ha KD, Brennan TM, Heyneker HL. Single-step assembly of a gene and entire plasmid from large numbers of oligodeoxyribonucleotides. Gene. 1995;164(1):49-53.

21. Cóceres VM, Becher ML, De Napoli MG, Corvi MM, Clemente M, Angel SO. Evaluation of the antigenic value of recombinant Toxoplasma gondii HSP2O to detect specific immunoglobulin $\mathrm{G}$ antibodies in Toxoplasma infected humans. Exp Parasitol. 2010;126(2):263-6.

22. Kong J-T, Grigg ME, Uyetake L, Parmley S, Boothroyd JC. Serotyping of Toxoplasma gondii infections in humans using synthetic peptides. J Infect Dis. 2003;187(9):1484-95.

23. Gordeeva TL, Borschevskaya LN, Sineoky SP. Improved PCR-based gene synthesis method and its application to the Citrobacter freundii phytase gene codon modification. J Microbiol Methods. 2010;81(2):147-52.

\section{Submit your next manuscript to BioMed Central and take full advantage of:}

- Convenient online submission

- Thorough peer review

- No space constraints or color figure charges

- Immediate publication on acceptance

- Inclusion in PubMed, CAS, Scopus and Google Scholar

- Research which is freely available for redistribution

Submit your manuscript at www.biomedcentral.com/submit
C) Biomed Central 